\title{
Microbubble generation in organic solvents by porous membranes with different membrane wettability
}

Bingqi Xie ${ }^{\text {a, b}}$, Caijin Zhou ${ }^{\text {a }}$, Xiaoting Huang a , Junxin Chen ${ }^{\mathrm{a}}$, Xiangdong $\mathrm{Ma}^{\mathrm{b}}$, Jisong Zhang a, *

aThe State Key Laboratory of Chemical Engineering, Department of Chemical Engineering, Tsinghua University, Beijing 100084, China

${ }^{\text {b}}$ The Department of Materials Science and Engineering, China University of Mining \& Technology (Beijing), Beijing 100083, China
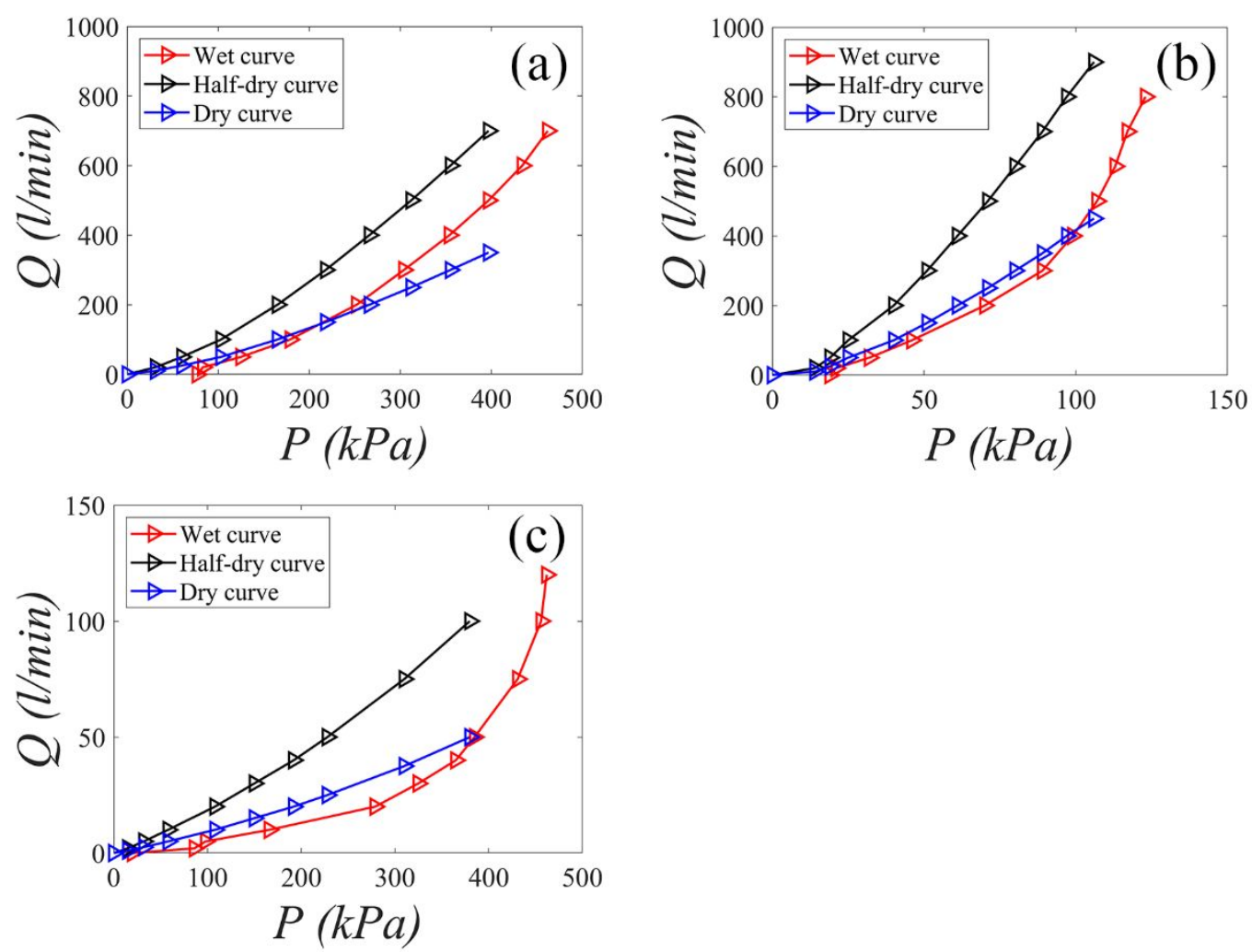

Figure S1. The test data of bubble point pressure: (a) $0.2 \mu \mathrm{m}$ ceramic membrane, (b) $1.4 \mu \mathrm{m}$ ceramic membrane, (c) $0.2 \mu \mathrm{m}$ PTFE membrane. 
(a)
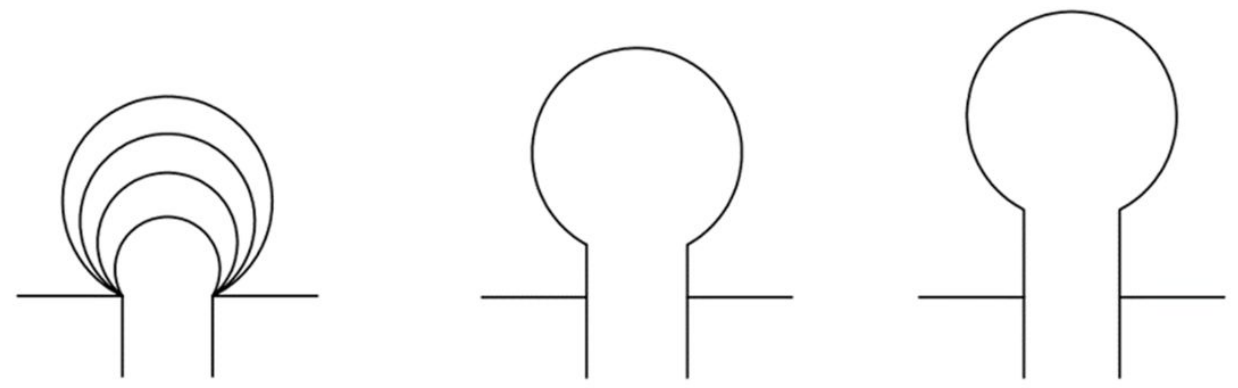

(b)
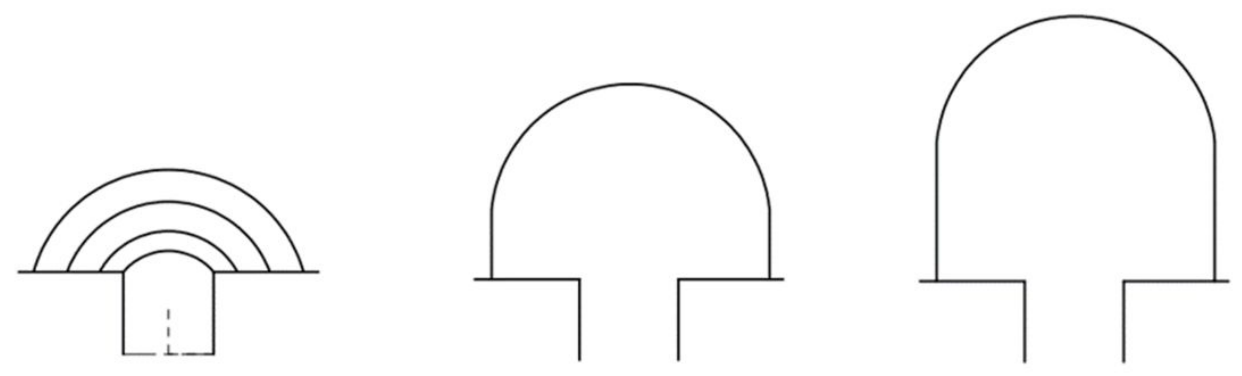

Figure S2. The process of microbubble formation in different wettability membrane:

(a) hydrophilic, (b) hydrophobic.

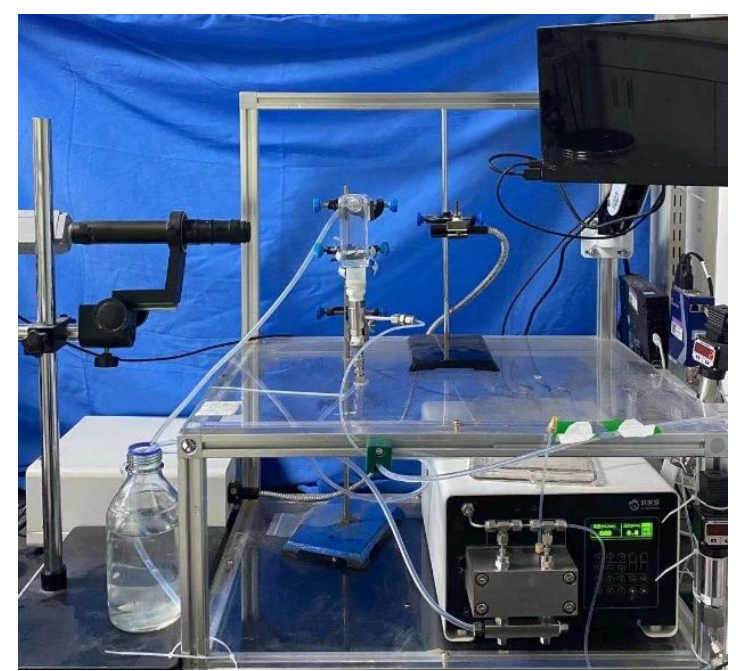

Figure S3. The picture of experimental setup. 